\title{
The In Vitro Functional Impairment of Thyroid Hormone Receptor Alpha 1 Isoform Mutants Is Mainly Dictated by Reduced Ligand Sensitivity
}

\author{
Karn Wejaphikul, ${ }^{1,2}$ Anja L.M. van Gucht, ${ }^{1}$ Stefan Groeneweg, ${ }^{1}$ W. Edward Visser, \\ Theo J. Visser, ${ }^{1, *}$ Robin P. Peeters, ${ }^{1}$ and Marcel E. Meima ${ }^{1}$
}

Background: Thyroid hormone (TH) acts on TH receptors (TRs) and regulates gene transcription by binding of TRs to TH response elements (TREs) in target gene promoters. The transcriptional activity of TRs is modulated by interactions with TR-coregulatory proteins. Mutations in TR $\alpha$ cause resistance to thyroid hormone alpha (RTH $\alpha)$. In this study, we analyzed if, beyond reduced triiodothyronine (T3) affinity, altered interactions with cofactors or different TREs could account for the differential impaired transcriptional activity of different mutants.

Methods: We evaluated four mutants derived from patients (D211G, M256T, A263S, and R384H) and three artificial mutants at equivalent positions in patients with $\mathrm{RTH} \beta(\mathrm{T} 223 \mathrm{~A}, \mathrm{~L} 287 \mathrm{~V}$, and $\mathrm{P} 398 \mathrm{H})$. The in vitro transcriptional activity was evaluated on TRE-luciferase reporters (DR4, IR0, and ER6). The affinity for T3 and interaction with coregulatory proteins (nuclear receptor corepressor 1 [NCoR1] and steroid receptor coactivator 1 [SRC1]) were also determined.

Results: We found that the affinity for T3 was significantly reduced for all mutants, except for TR $\alpha 1-\mathrm{T} 223 \mathrm{~A}$. The reduction in the T3 sensitivity of the transcriptional activity on three TREs, the dissociation of the corepressor NCoR1, and the association of the coactivator SRC1 recruitment for each mutant correlated with the reduced affinity for T3. We did not observe mutation-specific alterations in interactions with cofactors or TREs.

Conclusions: In summary, the degree of impaired transcriptional activity of mutants is mainly determined by their reduced affinity for $\mathrm{T} 3$.

Keywords: thyroid hormone receptor, thyroid hormone response elements, resistance to thyroid hormone, thyroid hormone action, receptor mutation, coregulatory proteins

\section{Introduction}

G ENOMIC ACTIONS OF THYROID HORMONE (TH) are regulated by binding of the active form of $\mathrm{TH}$, triiodothyronine (T3), to its nuclear $\mathrm{TH}$ receptors (TRs), which act predominantly as heterodimers with retinoid $\mathrm{X}$ receptors (RXRs) on TH response elements (TREs) in the promoter region of target genes $(1,2)$. TREs usually consist of twoconsensus half-sites that can be organized in direct repeats (DRs), inverted repeats (IRs), and everted repeats (ERs), separated by a stretch of random nucleotides of various lengths, of which the DR4-TRE is the predominant TRbinding form (3-6). In the absence of ligand, TRs repress target gene transcription by recruitment of corepressors such as nuclear receptor corepressor 1 (NCoR1). Binding of T3 causes dissociation of the corepressors and allows coactivators, such as steroid receptor coactivator 1 (SRC1), to bind to the TR, resulting in activation of gene transcription $(1,7)$.

Mutations in the ligand binding domain (LBD) of TR $\alpha 1$ cause resistance to thyroid hormone alpha $(\mathrm{RTH} \alpha)$, which was first described in $2012(8,9)$. The phenotype of RTH $\alpha$ patients includes growth retardation, macrocephaly, constipation, intellectual disability, anemia, and a high (F)T3/ (F)T4 ratio $(10,11)$. To date, 22 mutations (in a total of 37 patients) have been reported as a cause of RTH $\alpha$. These mutations can be categorized into two groups based on the type of mutation. The first group consists of truncating mutations caused by nonsense or frameshift mutations that create premature stop codons and shorten the length of the LBD (8,9,12-14). This structural alteration completely

\footnotetext{
${ }^{1}$ Department of Internal Medicine, Academic Center for Thyroid Diseases, Erasmus MC, Rotterdam, The Netherlands.

${ }^{2}$ Department of Pediatrics, Faculty of Medicine, Chiang Mai University, Chiang Mai, Thailand.

*Deceased March 21, 2018.
} 
abolishes T3 affinity and T3-induced transcriptional activity of $\mathrm{TR} \alpha 1$. The second group consists of missense mutations that result in single amino acid substitutions in the LBD (10,13-20). These mutant receptors can still bind T3, but with a lower affinity than wild-type (WT) receptors.

There is a variety in the clinical phenotype of RTH $\alpha$ patients. Patients with truncating mutations generally have a more severe phenotype than patients with missense mutations (9,12-14). Within the latter group, there are notable differences in the neurocognitive features $(14,17,20)$. At present, it is unclear whether these differences are solely explained by differences in $\mathrm{T} 3$ binding. In $\mathrm{RTH} \beta$, mutation-specific effects on particular TREs and differences in interaction with coactivators versus corepressors have been described (2124). Here, we studied if mutation-specific effects on TRE or cofactor binding are present in a selected series of seven specific TR $\alpha 1$ missense mutations.

\section{Materials and Methods}

\section{Plasmid constructs}

The coding sequence (cDNA) of full-length TR $\alpha 1$ fused at the $5^{\prime}$ end to the FLAG epitope or to VP16 was cloned into the pcDNA3 (9) and the pCMX expression vectors (18), respectively, as previously described. Selected TR $\alpha 1$ missense mutations were introduced into pcDNA3-FLAG TR $\alpha 1$ and pCMX-VP16 TR $\alpha 1$ expression vectors using the QuikChange II Mutagenesis kit (Align Technologies, Amstelveen, The Netherlands) (see Supplementary Table S1 for primers) and confirmed by Sanger sequencing.

The luciferase reporter constructs containing the DR4, IR0, or ER6 TRE configurations (TRE-tkLuc) (25), the luciferase reporter construct containing the Gal4 binding site (UAStkLuc), and the pSG424 expression vector constructs containing the Gal4 DNA-binding domain (GAL4-DBD) fused to the interacting domains of NCoR1 or SRC1 (8) have all been described elsewhere.

\section{[25I]T3 competitive binding assays}

$\left[{ }^{125} \mathrm{I}\right] \mathrm{T} 3$ competitive binding assays were performed as previously described (26). In brief, WT and mutant FLAG$\mathrm{TR} \alpha 1$ proteins were synthesized using the $\mathrm{TnT}^{\circledR}$ T7 Quick Coupled Transcription/Translation System (L1170; Promega, Leiden, The Netherlands). The proteins were incubated with $0.02 \mathrm{nM}$ of $\left[{ }^{125} \mathrm{I}\right] \mathrm{T} 3$ [prepared in-house as previously described (27)] and 0-10,000 nM unlabeled T3 (Cat. No. T2877; Sigma-Aldrich) at $30^{\circ} \mathrm{C}$ for 2 hours. The input of WT and mutant FLAG-TR $\alpha 1$ proteins' lysate was adjusted to obtain 10-20\% maximal [ $\left.{ }^{125} \mathrm{I}\right] \mathrm{T} 3$ binding, to prevent the ligand depletion effect. TR-bound $\left[{ }^{125} \mathrm{I}\right] \mathrm{T} 3$ was measured and calculated as a percentage $\left[{ }^{125} \mathrm{I}\right] \mathrm{T} 3$ input. The dissociation constant $(\mathrm{Kd})$ was computed by GraphPad Prism 5.0 (GraphPad, La Jolla, CA).

\section{In silico model prediction}

The various TR $\alpha 1$ mutations were introduced into the WT T3-bound TR $\alpha 1$ crystal structure [PDB-ID: 2H77 (28)] using the side-chain substitution and optimization tools of the YASARA Structure software (YASARA Bioscience GmbH, Vienna, Austria) (29). The structural models of the TR $\alpha 1$ mutants have been processed and compared with the WT
TR $\alpha 1$ structure as previously described (20). Given their location outside the ligand-binding pocket, the D211G, T223A, $\mathrm{R} 384 \mathrm{H}$, and $\mathrm{P} 398 \mathrm{H}$ mutant models were compared with WT after additional molecular dynamic simulations in an AMBER force field with water as a solvent to investigate their impact on the structural integrity of the receptor.

Ligand-binding energy was calculated using the BindEnergy command implemented in YASARA Structure software, which calculates the in vacuo binding energy in NOVA force field without considering solvation effects (30). As such, this approach is suitable for detecting changes in binding energy by mutations that affect substrate interactions directly, and not for those having indirect effects. A high value indicates a favorable T3 binding.

\section{Cell culture and transfection}

JEG-3 cells (ECACC Cat. No. 92120308, RRID:CVCL_ 0363; Sigma-Aldrich) were cultured in 24-well plates using the growth medium (Dulbecco's Modified Eagle Medium (DMEM)/F12 supplemented with 9\% fetal bovine serum (FBS), $100 \mathrm{nM} \mathrm{Na}_{2} \mathrm{SeO}_{3}, 100 \mathrm{U} / \mathrm{mL}$ penicillin, and $100 \mu \mathrm{g} / \mathrm{mL}$ streptomycin) and transfected as previously described $(19,26)$. Briefly, 20 ng of FLAG-TR $\alpha 1$ plasmid was cotransfected with $120 \mathrm{ng}$ TRE-tkLuc reporter construct for transcriptional activity assays. For protein/protein interaction (mammalian twohybrid) assays, $20 \mathrm{ng}$ of TR $\alpha 1$ fused to the transcriptional activator VP16 (VP16-TR $\alpha 1$ ) plasmid was cotransfected with $20 \mathrm{ng}$ of NCoR1 or SRC1 fused to the DNA binding domain of Gal4 (GAL4-NCoR1 or GAL4-SRC1) and $120 \mathrm{ng}$ of UAStkLuc. In both assays, $20 \mathrm{ng}$ pMaxGFP plasmid was cotransfected to monitor the transfection efficiency. All of the transfection processes were performed in TH-depleted medium (DMEM/F12 supplemented with $9 \%$ charcoal-stripped FBS) using X-tremeGENE 9 transfection reagent (Roche Diagnostics, Almere, NL). After a 24-hour transfection, cells were stimulated for 24 hours with 0-10,000 nM T3 in DMEM/ F12 supplemented with $0.1 \%$ bovine serum albumin (BSA).

\section{Immunoblotting}

The expression of FLAG- and VP16-TR $\alpha 1$ proteins in cells was verified by immunoblotting nuclear extracts of JEG-3 cells transfected with WT or mutant TR expression constructs as previously described $(19,26)$. The receptors were probed with 1:1000 dilution of FLAG-M2 antibody (\#F1804; SigmaAldrich) or 1:1000 dilution of VP16 antibody (sc-7545; Santa Cruz Biotechnology). Histone 3 protein was detected with 1:1000 dilution of Histone 3 (H3; 1B1B2) antibody (\#14269; Cell Signaling Technology) to verify comparable protein input. Bands were visualized on the Alliance 4.0 Uvitec platform (Uvitec Ltd.) by enhanced chemiluminescence (Thermo Fisher Scientific).

\section{Electrophoretic mobility shift assays}

A double-stranded overlapping oligonucleotide probe containing DR4-TRE was obtained by annealing $25 \mathrm{ng}$ of sense and antisense oligonucleotide $5^{\prime}$ end labeling with fluorescence dye (5'IRDye $\left.{ }^{\circledR} 700\right)$ (Integrated DNA Technologies, Leuven, Belgium) at $80^{\circ} \mathrm{C}$ for 5 minutes (sense oligonucleotides: 5'AGGACGTTGGGGTTAGGGGAGGACAGTGGAC-3', antisense oligonucleotides: $5^{\prime}$-GTCCACTGTCCTCCCC 
TAACCCCAACGTCCT-3', hexanucleotide half-sites of DR4-TRE are underlied). The DR4-TRE probe was diluted to a final concentration of $1 \mathrm{ng} / \mu \mathrm{L}$ in $50 \mu \mathrm{L} 1 \times \mathrm{TE}$ buffer $(10 \mathrm{mM}$ Tris $\mathrm{HCl} \mathrm{pH} 8.0,1 \mathrm{mM}$ ethylenediaminetetraacetic acid (EDTA)). FLAG-TR $\alpha 1$ and RXR $\alpha$ proteins were synthesized by the TnT T7 Quick Coupled Transcription/ Translation System (L1170; Promega). Since equal amounts of in vitro translated receptors were detected on an immunoblot (data not shown), we decided to use $1 \mu \mathrm{L}$ of in vitro translated WT or mutant FLAG-TR $\alpha 1$ and $2 \mu \mathrm{L}$ of in vitro translated $\operatorname{RXR} \alpha$. TR and $\operatorname{RXR} \alpha$ were coincubated in the dark with $0.5 \mu \mathrm{L}$ of DR4-TRE probe, and $2 \mu \mathrm{g}$ of poly(deoxyinosinic-deoxycytidylic) acid sodium salt (SC286691; Santa Cruz Biotechnology) in a final $10 \mu \mathrm{L}$ of binding buffer $(10 \times$ binding buffer: $100 \mathrm{mM}$ Tris, $10 \mathrm{mM}$ EDTA, $1 \mathrm{M} \mathrm{KCl}, 1 \mathrm{mM}$ DDT, $50 \%$ glycerol, $0.1 \mathrm{mg} / \mathrm{mL}$ BSA) for 30 minutes at room temperature. Gel electrophoresis was performed on 6\% DNA retardation gel (EC6365BOX; Invitrogen). The TR-DNA complexes and residual unbound probe were visualized using an Odyssey ${ }^{\circledR}$ imaging system (LI-COR, Leusden, The Netherlands).

\section{Luciferase assays}

Luciferase activity was determined using the Dual Glo Luciferase kit (E2940; Promega). Luciferase and GFP activities were measured by a luminometer $\left(\right.$ Victor $^{\mathrm{TM}} \mathrm{X} 4$; PerkinElmer, Groningen, The Netherlands). Half-maximal effective $\mathrm{T} 3$ concentration $\left(\mathrm{EC}_{50}\right)$, half-maximal inhibitory $\mathrm{T} 3$ concentration $\left(\mathrm{IC}_{50}\right)$, and \%WT maximal response were analyzed using GraphPad Prism 5.0 (GraphPad).

\section{Statistical analysis}

The statistical differences between WT and mutants were analyzed by one-sample $T$-tests. The statistical differences of fold changes of $\log \mathrm{Kd}, \log \mathrm{EC}_{50}$, and $\log \mathrm{IC}_{50}$ between WT and mutants were determined by one-way analysis of variance with Tukey's post test. Statistical significance was considered at $p$-values $<0.05$.

\section{Results}

\section{Selection of mutants}

We tested seven TR $\alpha 1$ mutants, of which four were derived from $\mathrm{RTH} \alpha$ patients [D211G (19), M256T (20), $\mathrm{A} 263 \mathrm{~S}$, and R384H (14)]. These mutations covered the three CpG-rich regions of the LBD of TR $\alpha 1$ that are equivalent to the mutation-prone hotspots of the TR $\beta 1$ receptor, namely R384H in cluster 1, M256T and A263S in cluster 2 , and $\mathrm{D} 211 \mathrm{G}$ in cluster 3 . The other three mutations were derived from RTH $\beta$ patients. TR $\alpha 1-\mathrm{P} 398 \mathrm{H}$ (cluster 1 ), the equivalent of TR $\beta 1-\mathrm{P} 452 \mathrm{H}$, gave rise to an unusual phenotype that included obesity and marked metabolic disturbances in a murine model for $\mathrm{RTH} \alpha$ (31). TR $\alpha 1$ T223A (cluster 3 ) is the equivalent of TR $\beta 1-T 277 \mathrm{~A}$, which was previously shown to specifically impair transcriptional activity on an ER6-TRE and diminish affinity for SRC-1 (24). Finally, TR $\alpha 1-\mathrm{L} 287 \mathrm{~V}$ (cluster 2) is the equivalent of TR $\beta 1-L 341 \mathrm{~V}$, a recently identified mutation that causes a strong decrease in T3-binding affinity and a concomitant reduction in the $\mathrm{T} 3$ sensitivity of transcriptional activity and cofactor recruitment (26).

\section{T3 binding affinity of the TR $\alpha 1$ mutants}

We first determined the binding affinity of in vitro translated mutant receptors using a $\left[{ }^{125} \mathrm{I}\right] \mathrm{T} 3$ competitive binding assay. The $\left[{ }^{125} \mathrm{I}\right] \mathrm{T} 3$ binding curves were shifted to the right for most mutants (Fig. 1A), which reflects a higher required dose of T3 to saturate binding and hence a lower binding affinity. The dissociation constant $(\mathrm{Kd})$, which is the concentration of $\mathrm{T} 3$ at which half the binding sites are occupied, varied between mutants (Fig. 1B and Supplementary Table S2). TR $\alpha 1-M 256$ T showed the lowest affinity, as illustrated by the highest Kd of all mutants (160-fold higher than WT). Binding of T3 was similarly affected for TR $\alpha 1-\mathrm{D} 211 \mathrm{G}$ (Kd 25-fold higher than WT), -R384H (25-fold), -L287V (19-fold), and -P398H (17fold), but significantly less impaired for TR $\alpha 1-\mathrm{A} 263 \mathrm{~S}$ (Kd 5-fold higher than WT), whereas the Kd of TR $\alpha 1-T 223 \mathrm{~A}$ was not different from WT. These data indicate that the binding affinity is reduced to a different extent for the different mutants.

\section{In silico model of mutant TR $\alpha 1$}

Structural modeling was used to validate our in vitro studies. The side chains of A263, M256, and L287 face the ligand binding pocket (Fig. 2A, B), and are predicted to make direct interactions with T3 (Supplementary Fig. S1). The hydrophobic interaction between the side chain of A263 and the inner ring of T3 is lost in the A263S mutant. As previously reported (20), the M256T abrogates the direct interactions of M256 with T3 and simultaneously disturbs the structural niche accommodating the outer ring of T3. In analogy to the predicted in silico effects of the L $341 \mathrm{~V}$ mutant in TR $\beta 1$ (26), the L287V mutant disrupts the direct hydrophobic interaction of L287 with T3. In agreement with our in vitro studies, all three mutations reduced the calculated T3-binding energy compared with WT TR $\alpha 1$ in the order M256T $>$ L287V $>A 263 S$ (Supplementary Fig. S1D). Due to their location outside the binding pocket, the side chains of D211, R384, P398 (facing other internal domains), and T223 (facing the external protein surface) do not make direct contact with T3 (Fig. 2A, C), which prevents reliable in silico prediction of their impact on binding affinity. Structural modeling revealed extensive structural changes for the D211G (predominantly within the loop connecting $\mathrm{H} 2$ and $\mathrm{H} 3$ ), R384H, and $\mathrm{P} 398 \mathrm{H}$ (predominantly $\mathrm{H} 11$ and H12) mutants, whereas the T223A mutant displayed only minor local structural changes of the backbone configuration (Fig. 2C). These observations may well explain the differential effects of these mutations on in vitro binding affinity.

\section{Heterodimerization of TR $\alpha 1$ mutants with $R X R \alpha$}

To determine whether the dimerization of the mutants with RXR and binding of the dimer to DNA were affected, we performed electrophoretic mobility shift assays with in vitro translated WT or mutant $\mathrm{TR} \alpha 1$ and $\mathrm{RXR} \alpha$ on a fluorescently labeled DR4-TRE (Supplementary Fig. S2). The result showed that only a coincubation of $\operatorname{TR} \alpha 1$ and $\operatorname{RXR} \alpha$ could shift the DR4-TRE oligonucleotide probe upward. The upward shift of the probe was not observed in an incubation of WT TR $\alpha 1$ or RXR $\alpha$ alone. These findings indicate that the WT receptors exclusively bound to the DR4-TRE as heterodimers with $\operatorname{RXR} \alpha$, which is in contrast to the $\operatorname{TR} \beta 1$ isoform that can bind as both homo- and heterodimers $(32,33)$. The intensity of the heterodimer band was similar to WT for all mutants. In 
A
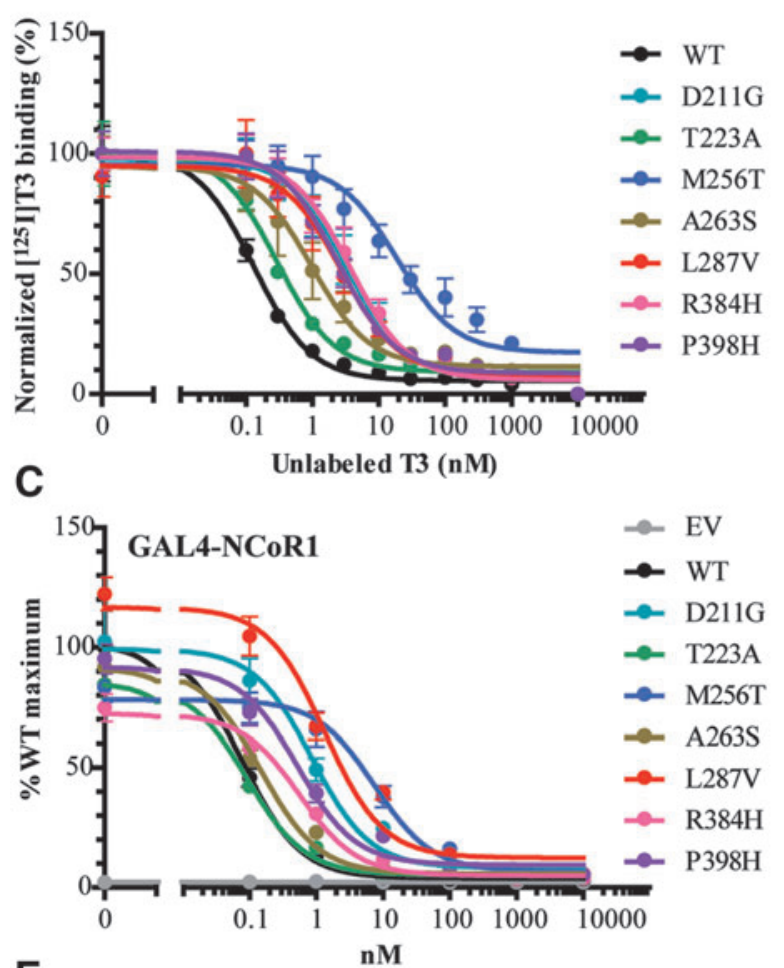

E

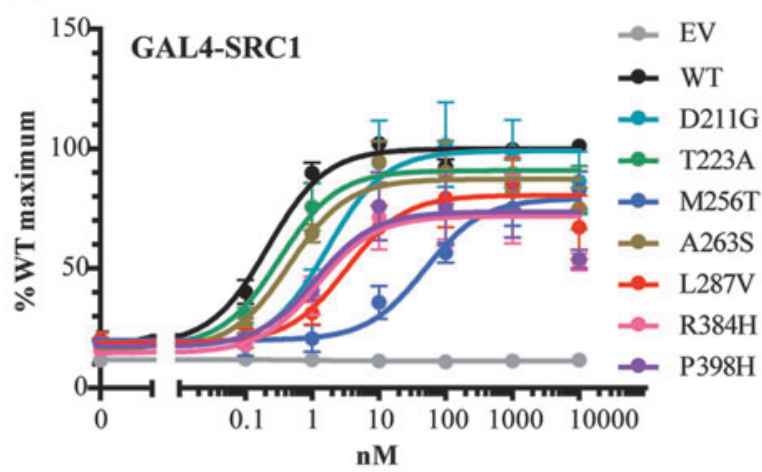

B

D
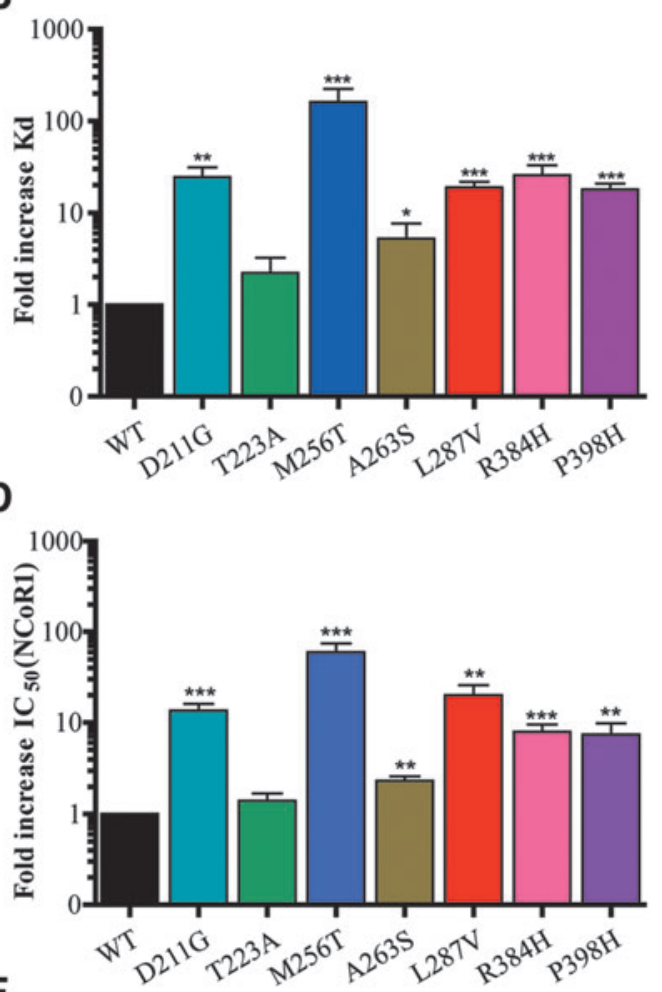

$\mathbf{F}$

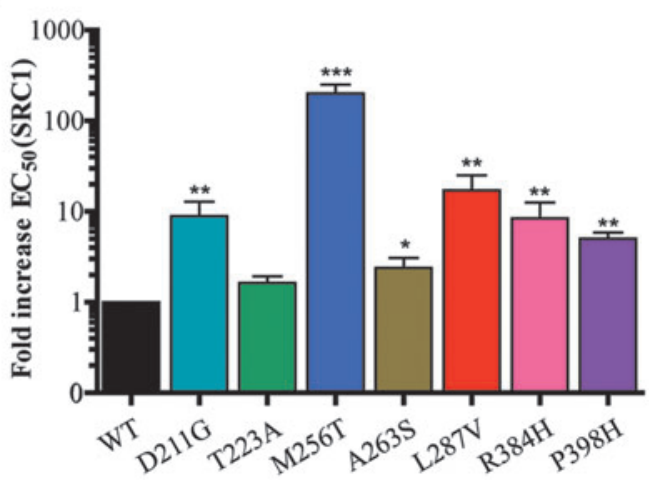

FIG. 1. (A, B) $\left[{ }^{125} \mathrm{I}\right] \mathrm{T} 3$ competitive binding assays of the TR $\alpha 1 \mathrm{WT}$ and mutants. (A) The dissociation curves of all mutants are shifted to the right, indicative of a reduced T3 binding affinity. (B) The fold increase of the Kd is various between mutants (one-sample $T$-test, $* p<0.05, * * p<0.01, * * * p<0.001$ ). Data presented as mean \pm SEM from four independent experiments performed in duplicate. (C-F) Mammalian two-hybrid assays demonstrating TR $\alpha 1$-cofactor interactions. (C) T3-induced GAL4-NCoR1 dissociation and (E) GAL4-SRC1 association curves show a various degree of reduced T3-dependent NCoR1 release and SRC1 recruitment of mutants, respectively. These are indicated by the right shift of the curves and higher $\mathrm{IC}_{50}-\mathrm{NCoR} 1$ or $\mathrm{EC}_{50}-\mathrm{SRC} 1$ than that of WT. (D) The fold increases in $\mathrm{IC}_{50}$ for the $\mathrm{NCoR} 1$ dissociation are similar to (E) the fold increase in $\mathrm{EC}_{50}$ for the SRC1 association for each mutation (the fold increases $\mathrm{IC}_{50}-\mathrm{NCoR} 1$ and $\mathrm{EC}_{50}-\mathrm{SRC} 1$ of the mutants were compared with WT by one-sample $T$-test; $\left.* p<0.05, * * p<0.01, * * * p<0.001\right)$. Data presented as mean \pm SEM from at least four independent experiments performed in triplicate. NCoR1, nuclear receptor corepressor 1; SEM, standard error of the mean; SRC1, steroid receptor coactivator 1; T3, triiodothyronine; WT, wild type.

addition, heterodimer binding to the DR4-TRE was independent of the presence of T3 for WT and mutants. These results show that heterodimerization with $\mathrm{RXR} \alpha$ and binding to the DR4-TRE are not affected in any of the mutants.

\section{Receptor-cofactor interaction of the TR $\alpha 1$ mutants}

To determine whether cofactor recruitment of the mutants was impaired, we next evaluated the interaction of the mutants with the corepressor NCoR1 and the coactivator SRC1, which directly bind to TRs and play a crucial role in receptor function $(1,7)$. In a mammalian two-hybrid assay, VP16-TR $\alpha 1$ activates a luciferase reporter (UAS-tkLuc) only when it interacts with GAL4-NCoR1 or -SRC1. As a measure for T3 dependence, we determined the concentration that gave halfmaximum dissociation of $\mathrm{NCoR} 1\left(\mathrm{IC}_{50}\right)$ and half-maximum association of SRC1 $\left(\mathrm{EC}_{50}\right)$. Stimulation of WT TR $\alpha 1$ with low concentrations of T3 $(0.1-1 \mathrm{nM})$ already resulted in dissociation 
A

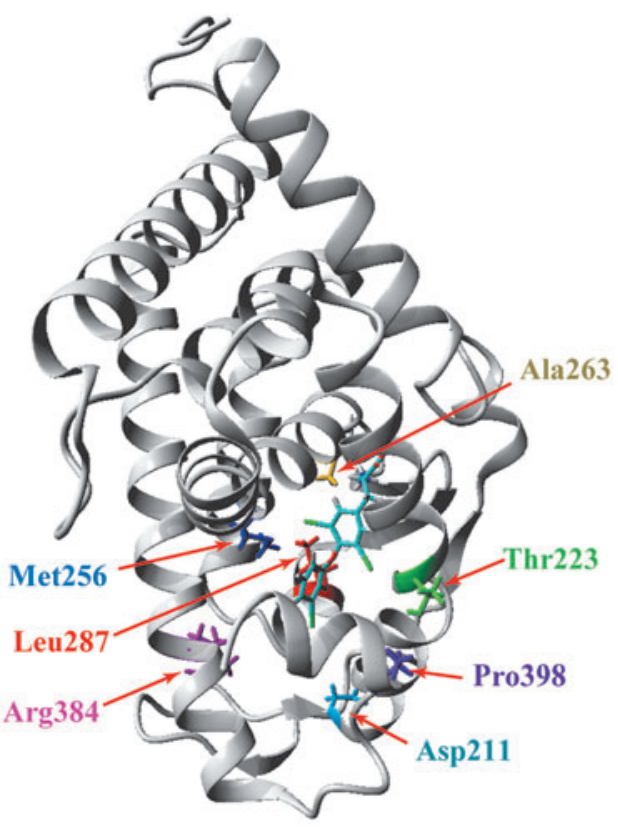

C

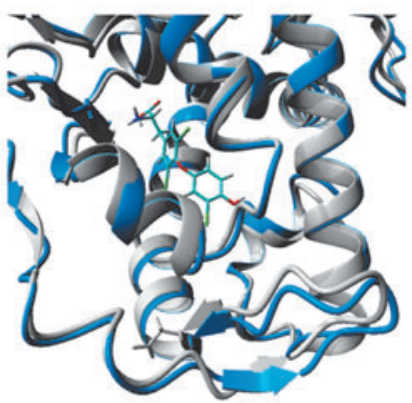

WT/R384H

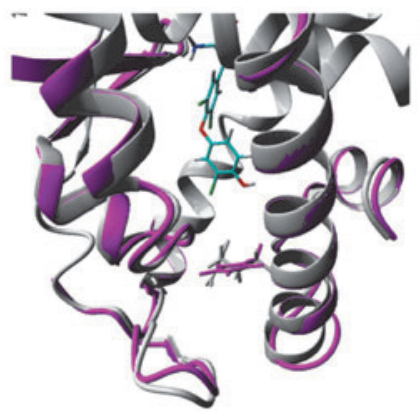

B

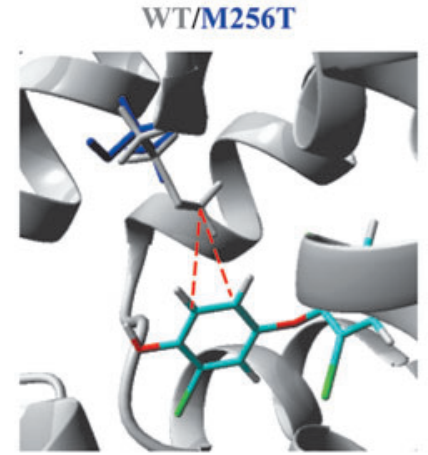

WT/M256T

WT/T223A

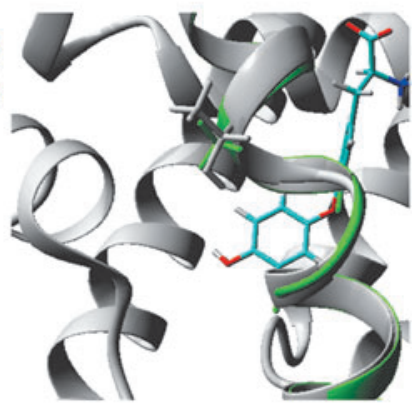

WT/P398H

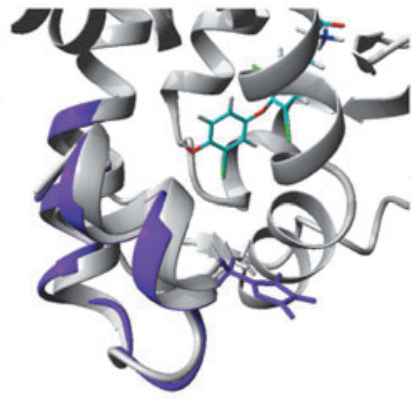

WT/L287V
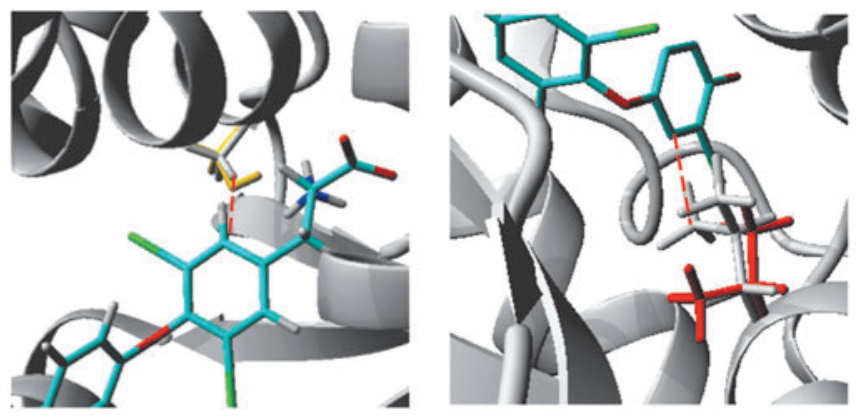

FIG. 2. (A) The WT TR $\alpha 1$ crystal structure in complex with T3 (PDB ID: $2 \mathrm{~h} 77$ ) in which the locations of the mutated residues studied are highlighted. (B) Close-up view of the TR $\alpha 1$ ligand-binding pocket, presented as an overlay of the WT crystal (gray) and indicated mutant models (colored). The side chains of the mutant residues are displayed in blue (M256T, left panel), orange (A263S, middle panel), and red (L287V, right panel), and of the corresponding WT residues in gray. Hydrophobic interactions between WT residues and T3 are indicated with a red dashed line. The interaction between mutant residues and T3 is not observed. For clarity, the small deviations in the carbon backbone structure are not displayed. (C) Close-up view of the overlay of the WT TR $\alpha 1$ structure and models with indicated mutations that affect residues outside the ligand-binding pocket. Mutant models are displayed in blue (D211G, left upper panel), green (T223A, right upper panel), pink (R384H, left lower panel), and purple (P398H, right lower panel), and WT TR $\alpha 1$ in gray. The T3 ligand is displayed in all panels in element color. All figures were created in YASARA Structure using PovRay imaging software.

of GAL4-NCoR1 ( $\left.\mathrm{IC}_{50} 0.08 \mathrm{nM}\right)$ and association of GAL4$\mathrm{SRC} 1\left(\mathrm{EC}_{50} 0.28 \mathrm{nM}\right)$. Most mutants required higher T3 concentrations to dissociate from NCoR1 (Fig. 1C) and recruit SRC1 (Fig. 1E). Consistent with the affinity for T3, TR $\alpha 1-$ $\mathrm{M} 256 \mathrm{~T}$ showed the highest $\mathrm{IC}_{50}$ for $\mathrm{NCoR} 1$ dissociation (60-fold higher than WT) and $\mathrm{EC}_{50}$ for SRC1 association (200fold) (Fig. 1D, F, Supplementary Fig. S3, and Supplementary Table S3). The TR $\alpha 1-\mathrm{D} 211 \mathrm{G}, \mathrm{L} 287 \mathrm{~V}, \mathrm{R} 384 \mathrm{H}$, and P398H mutants showed higher $\mathrm{IC}_{50^{-}} \mathrm{NCoR} 1$ dissociation and $\mathrm{EC}_{50^{-}}$ $\mathrm{SRC} 1$ association than WT but lower than TR $\alpha 1-\mathrm{M} 256 \mathrm{~T}$. The fold increase of $\mathrm{IC}_{50}$ and $\mathrm{EC}_{50}$ of these four mutations was similar. The $\mathrm{IC}_{50^{-}} \mathrm{NCoR} 1$ dissociation and $\mathrm{EC}_{50^{-}} \mathrm{SRC} 1$ association of A263S-TR $\alpha 1$ mutation were approximately twofold higher than WT, corresponding to the changes of its $\mathrm{Kd}$ in competitive binding assays. For TR $\alpha 1-\mathrm{T} 223 \mathrm{~A}$, the T3-induced NCoR1 dissociation and SRC1 association were similar to the WT receptor. We did not observe major differences in maximal binding of either NCoR1 or SRC-1 to mutants compared with WT, indicating that the affinity of the mutants for these cofactors is not markedly disturbed.

\section{Transcriptional activity of the TR $\alpha 1$ mutants}

We then tested the mutants for transcriptional activity using a reporter assay. For this, we cotransfected WT or mutant receptors into JEG-3 cells with constructs in which the coding sequence for firefly luciferase is under control of a DR4, IR0, or ER6-TRE. 
The T3-induced transcriptional activity on the DR4-TRE was impaired for most mutant receptors, as indicated by a rightward shift of the dose-response curves compared with WT and a concomitant increase in $\mathrm{EC}_{50}$, representing the $\mathrm{T} 3$ dose that is needed to achieve a half-maximal response (Fig. 3A and Supplementary Table S4). TR $\alpha 1-\mathrm{M} 256 \mathrm{~T}$ had the highest $\mathrm{EC}_{50}$ (100-fold higher than WT). The $\mathrm{EC}_{50}$ of TR $\alpha 1$ D211G, L287V, R384H, and P398H was $\sim 10$ to 20 -fold higher than that of WT. In contrast, the $\mathrm{EC}_{50}$ of TR $\alpha 1-\mathrm{A} 263 \mathrm{~S}$ and T223A was not significantly different from WT. The fold increase in $\mathrm{EC}_{50}$ tested on the IR0- and ER6-TREs of each mutant was not significantly different from that tested on the DR4-TRE (Fig. 3B-D), suggesting that the effects of these mutations are not TRE specific. Most of the mutants showed a similar maximal transcriptional activity as WT at supraphysiological T3 concentrations, with the exception of TR $\alpha 1-T 223 A$ on DR4-TRE and TR $\alpha 1-P 398 H$ on DR4- and IR0-TRE that were significantly lower than that of WT.

\section{Correlation between T3-affinity, cofactor binding, and transcriptional activity of TR $\alpha 1$ mutants}

Finally, to determine whether certain aspects of receptor regulation were proportionally stronger affected than that would be expected from the effect of the mutation on T3 binding, we correlated the fold increase of parameters for binding affinity, and T3-dependent activity and cofactor recruitment (Fig. 4). The fold increases in $\mathrm{IC}_{50}-\mathrm{NCoR} 1$, $\mathrm{EC}_{50}-\mathrm{SRC} 1$, and $\mathrm{EC}_{50}$ on DR4-TRE generally followed the same trend as the fold increase in $\mathrm{Kd}$ of each mutant with two exceptions. First, the fold increase in $\mathrm{EC}_{50^{-}} \mathrm{SRC} 1$ of M256T-TR $\alpha 1$ was slightly but significantly higher than its
$\mathrm{IC}_{50}-\mathrm{NCoR} 1$, which would suggest a marginally stronger effect of the mutation on T3-dependent SRC1 recruitment than NCoR1 release. Second, the fold increase in $\mathrm{Kd}$ of $\mathrm{R} 384 \mathrm{H}-\mathrm{TR} \alpha 1$ was slightly higher than its $\mathrm{IC}_{50}-\mathrm{NCoR} 1$. In both cases, however, this did not result in a significant effect on the $\mathrm{EC}_{50}$-DR4 TRE, indicating that these differences do not majorly contribute to the degree of functional impairment.

\section{Discussion}

In the current study, we report in vitro functional studies of seven TR $\alpha 1$ missense mutations. The main purpose was to investigate if other factors, beyond disturbed T3 binding, contribute to the functional impairment of TR $\alpha 1$ mutations. According to our results, the reduced affinity for $\mathrm{T} 3$ is the main factor that determines both the severity of impaired transcriptional activity and impaired TR-cofactor interaction of the mutants. In our series, we did not find evidence for mutation-specific effects on different TREs or coregulatory protein binding.

Our selection of mutants covered the equivalents of the three mutation-prone hotspots in TR $\beta 1$. We evaluated the effect of mutations on transcriptional activity by overexpressing WT or mutant receptors with a reporter gene under control of TREs. Since some TR $\beta 1$ mutants display TRE-selective defects, we included all three reported halfsite configurations (DR4, IR0, and ER6). As expected, the mutants had an impaired T3-dependent transcriptional activity, as illustrated by their dose-response curves with a clear shift to the right side of the WT curve and corresponding higher $\mathrm{EC}_{50}$ than WT. The degree of impaired transcriptional activity varied among the mutants and correlated with the reduced
A

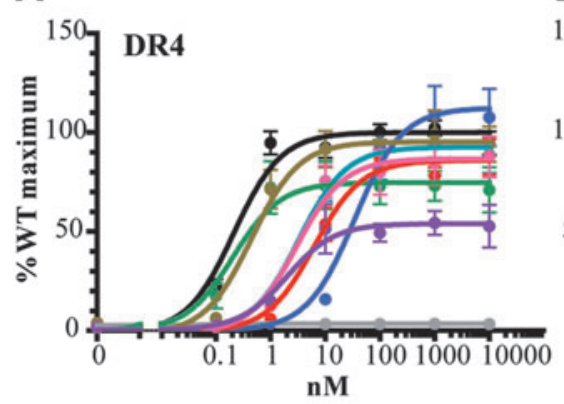

D

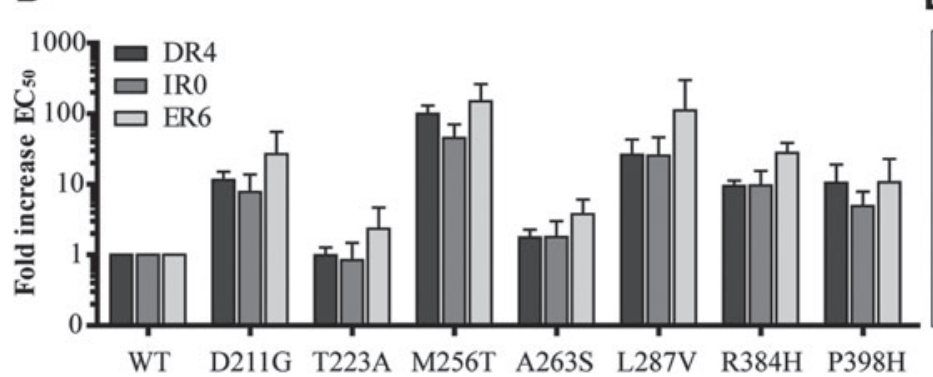

C

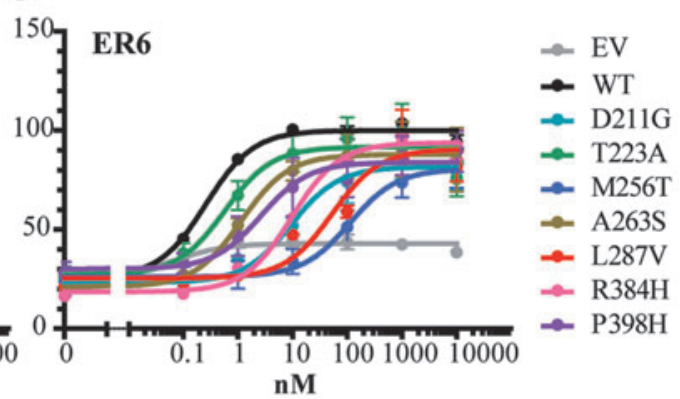

E

FIG. 3. The T3-induced transcriptional activity of TR $\alpha 1 \mathrm{WT}$ and mutants tested on three different TRE-luciferase reporter constructs. (A-C) The dose-response curves show a various degree of impaired transcriptional activity of mutants, as indicated by the right shift of the curves and higher $\mathrm{EC}_{50}$ than WT. (D) The fold increases of mutants' $\mathrm{EC}_{50}$ are various between mutations. The shift of $\mathrm{EC}_{50}$ on three TREs generally follows a similar trend for each mutation. Data presented as mean \pm SEM from at least three independent experiments performed in triplicate. (E) Immunoblot confirms the expression of WT and mutant FLAG-TR $\alpha 1$ in JEG-3 cells. TRE, TH response element. 


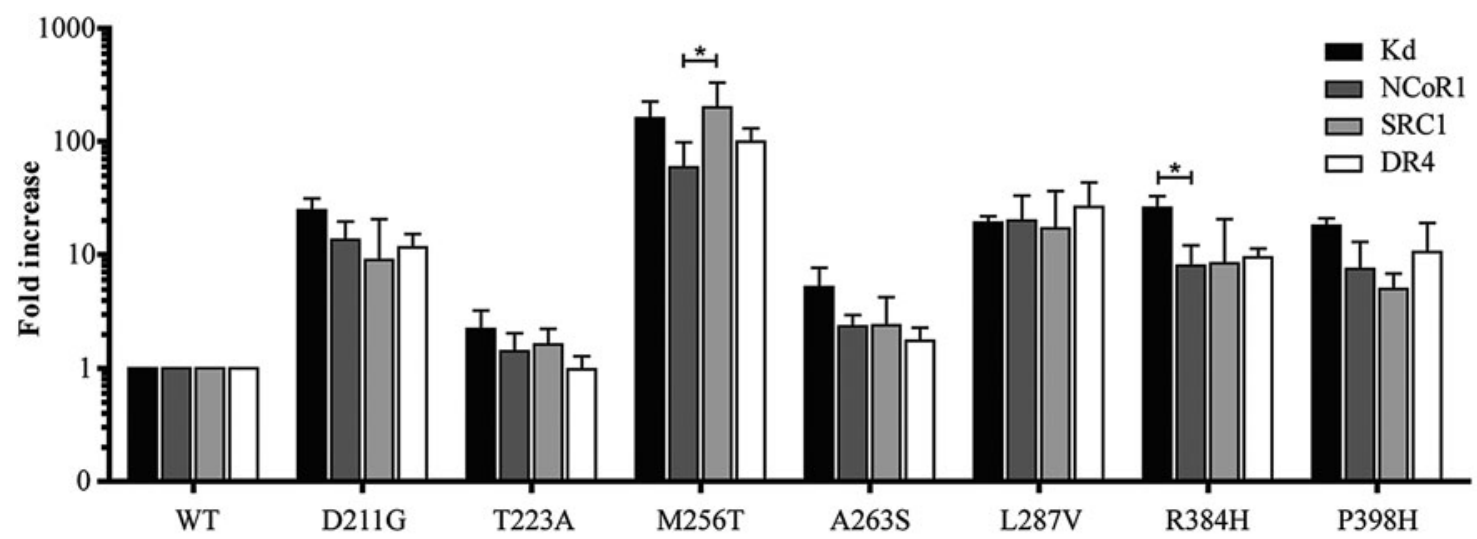

FIG. 4. Fold increases of $\mathrm{Kd}, \mathrm{IC}_{50}-\mathrm{NCoR} 1$ dissociation, $\mathrm{EC}_{50}-\mathrm{SRC} 1$ association, and $\mathrm{EC}_{50}$ of $\mathrm{T} 3$-induced transcriptional activity on the DR4-TRE. These fold increases are various among mutants but generally follow a similar trend for each mutant, except for M256T and R384H (one-way ANOVA with Tukey's post-test * $p<0.05$ ). ANOVA, analysis of variance; DR, direct repeat.

T3-binding energy of the mutants predicted by the in silico modeling and the reduction in $\mathrm{T} 3$ affinity from the in vitro binding assays. This finding is in line with previous reports of the other mutants derived from $\mathrm{RTH} \alpha$ patients $(8,12,15,25)$. In addition, the degree of impaired transcriptional activity seemed to be related to the severity of the phenotype of the $\mathrm{RTH} \alpha$ patients, especially the delayed motor development, which is much more prominent in the patients carrying TR $\alpha 1$ $\mathrm{D} 211 \mathrm{G}$ and $-\mathrm{R} 384 \mathrm{H}$ mutations than in the patient carrying a $\mathrm{TR} \alpha 1-\mathrm{A} 263 \mathrm{~S}$ mutation. This is in agreement with a previous report by Moran et al. which showed that the functional properties of two TR $\alpha 1$ mutations (A263V and L274P) correlate with the clinical features of the patients (18).

There was no TRE-selective reduction in T3-dependent receptor activity since the fold increase in $\mathrm{EC}_{50}$ on all three TREs was similar for each mutant. Of note, the T223A-TR $\alpha 1$ mutant did not show any differential effect on different TREs, which is in contrast with its equivalent TR $\beta 1-T 277 \mathrm{~A}$, which is selectively affected on an ER6-TRE (24). However, the maximal response of T223A and $\mathrm{P} 398 \mathrm{H}$ was lower than that of WT on the DR4- and IR0-TRE. This TRE-specific submaximal response has been previously reported in TR $\beta 1$-T277A (24); however, in these studies, the submaximal response was found on the DR4- and ER6-TRE. The TRE-specific transcriptional impairment may be caused by different patterns of dimer formation and cofactor recruitment among TREs $(34,35)$. Nevertheless, since numerous chromatin occupation studies have suggested that the DR4-TRE is the most important TRE playing a role in the in vivo TR transcription (3-6), the pattern of TR-regulating gene transcription is more likely to follow the in vitro result of the DR4-TRE rather than IR0- and ER6-TRE. Therefore, selective transcriptional impairment of the mutants on IR0- and ER6-TRE found in vitro may not have a large contribution in the severity of phenotypes in RTH patients.

It has been shown that a submaximal response of mutant receptors can be caused by impaired TR-cofactor interactions. For instance, the reduced maximal response of TR $\beta 1-\mathrm{T} 277 \mathrm{~A}$ was due to a reduced affinity for SRC-1, which could be rescued by overexpression of SRC-1 (24). Mutations at the residues adjacent to $\mathrm{P} 452$ of the $\mathrm{TR} \beta 1$ (homologous to P398 of TR $\alpha 1$ ), P453 and L454, were also unable to reach WT maximal response and have been shown to have a defective
TR-cofactor interaction that consequently affects transcriptional activity to a greater extent than what would be expected based on their reduced affinity for T3 $(25,36,37)$. We, therefore, evaluated the interaction of selected TR $\alpha 1$ mutants with the NCoR 1 corepressor and the SRC1 coactivator. Except for T223A, the mutants required higher T3 levels than WT to dissociate from NCoR1 and to associate with SRC1, illustrating the impaired T3-dependent TR-cofactor interaction of these mutants. However, the degree of impaired TR-cofactor interaction was similar to the reduced affinity for T3 for all selected mutants. In addition, the maximum binding of TR $\alpha 1$ T223A and -P398H was similar to WT. These findings suggest that these mutations alter the T3-dependent TR $\alpha 1$-cofactor recruitment via their reduced $\mathrm{T} 3$ affinity, but that the submaximal response is likely explained by another mechanism such as impaired interaction of the mutants with other nuclear cofactors. We also studied the heterodimerization property of the selected TR $\alpha 1$ mutants and found that none of them disturbed heterodimer formation on the DR4-TRE, suggesting that the submaximal response of these mutant receptors is not explained by altered heterodimerization with RXR.

To our knowledge, our study reports the in vitro functional impairment at different levels of the largest series of $\mathrm{TR} \alpha 1$ mutants to date, including four mutations derived from RTH $\alpha$ patients, which cover all three CpG-rich clusters of TR $\alpha 1$ that correspond with the mutation-prone hotspots of $\operatorname{TR} \beta 1$. However, the transcriptional activation of mutants in this study was only tested on the most abundant TRE configuration, DR4 (3-6), and the other two well-known TRE configurations, IR0 and ER6, which do not cover all natural TREs. Therefore, the results should be interpreted and applied cautiously. Our study also did not explore some issues that might complicate the phenotype of RTH patients, for instance, the negative transcriptional gene regulation by TRs and the effect of mutant TRs on WT receptor function, known as a dominant negative effect. In addition, our experiments were performed exclusively in vitro and mainly by the overexpressing system in JEG-3 cells, which might not be entirely comparable with the in vivo situation. Although JEG3 cells comprise a well-established model to study the impact of TR mutations, the results of which correlate with the severity of the clinical phenotype, it may not represent the 
situation in other cell types or tissues. Therefore, studies in different TR-overexpressing cell lines, or in models that rely on endogenously expressed mutant TRs (such as CRISPRCas9 genome editing or primary cells derived from patients) may substantiate our findings.

$\mathrm{RTH} \alpha$ patients are currently treated with levothyroxine (LT4) to normalize FT4 levels and reduce the hypothyroid state of tissues that predominantly express TR $\alpha 1$, which in some cases has been shown to ameliorate the developmental delay and chronic symptoms $(15,18,19)$; however, the working mechanism is yet unclear. Since FT4 and T3 levels are only marginally increased, it seems unlikely that this treatment results in a significant occupation of receptors that have a 10-100-fold reduction in ligand affinity, but rather increases the number of activated WT receptors. Given that the functional defects of TR $\alpha 1$ missense mutants are driven by their reduced ligand affinity, agonists that provide a better fit to the altered ligand-binding pockets could, therefore, be a tailor-made treatment. Although such agonists are currently lacking, the finding that some TR $\beta 1$ mutants are more efficiently dissociated from NCoR1 by the natural T3 analogue triiodoacetic acid, which is sometimes used to suppress FT4 levels in $\mathrm{RTH} \beta$ patients, and the TR antagonist NH-3 (38) shows that such an approach may be viable.

In summary, this study demonstrates that the severity of impaired transcriptional activity of mutant $\mathrm{TR} \alpha 1$ receptors is mainly determined by the reduced affinity for T3. These mutations also alter TR-cofactor interactions to the same magnitude as the T3 binding defect. However, further studies are required to extensively evaluate the in vivo consequences of the TR $\alpha 1$ mutations.

\section{Acknowledgment}

We thank Prof. V. Krishna Chatterjee (Wellcome-MRC Institute of Metabolic Science, University of Cambridge, United Kingdom) for kindly providing some of the plasmids used in this study.

\section{Author Disclosure Statement}

No competing financial interests exist.

\section{Funding Information}

This work is supported by Zon-MWTOP grant 91212044 and an Erasmus MC Medical Research Advisory Committee (MRACE) grant (R.P.P, M.E.M), and the Chiang Mai University (K.W.).

\section{Supplementary Material}

Supplementary Figure S1

Supplementary Figure S2

Supplementary Figure S3

Supplementary Table S1

Supplementary Table S2

Supplementary Table S3

Supplementary Table S4

\section{References}

1. Cheng SY, Leonard JL, Davis PJ 2010 Molecular aspects of thyroid hormone actions. Endocr Rev 31:139-170.
2. Flamant F, Cheng SY, Hollenberg AN, Moeller LC, Samarut J, Wondisford FE, Yen PM, Refetoff S 2017 Thyroid hormone signaling pathways: time for a more precise nomenclature. Endocrinology 158:2052-2057.

3. Chatonnet F, Guyot R, Benoit G, Flamant F 2013 Genomewide analysis of thyroid hormone receptors shared and specific functions in neural cells. Proc Natl Acad Sci U S A 110:E766-E775.

4. Ayers S, Switnicki MP, Angajala A, Lammel J, Arumanayagam AS, Webb P 2014 Genome-wide binding patterns of thyroid hormone receptor beta. PLoS One 9:e81186.

5. Grontved L, Waterfall JJ, Kim DW, Baek S, Sung MH, Zhao L, Park JW, Nielsen R, Walker RL, Zhu YJ, Meltzer PS, Hager GL, Cheng SY 2015 Transcriptional activation by the thyroid hormone receptor through ligand-dependent receptor recruitment and chromatin remodelling. Nat Commun 6:7048.

6. Ramadoss P, Abraham BJ, Tsai L, Zhou Y, Costa-e-Sousa RH, Ye F, Bilban M, Zhao K, Hollenberg AN 2014 Novel mechanism of positive versus negative regulation by thyroid hormone receptor betal (TRbeta1) identified by genome-wide profiling of binding sites in mouse liver. J Biol Chem 289:1313-1328.

7. Astapova I 2016 Role of co-regulators in metabolic and transcriptional actions of thyroid hormone. J Mol Endocrinol 56:73-97.

8. Bochukova E, Schoenmakers N, Agostini M, Schoenmakers E, Rajanayagam O, Keogh JM, Henning E, Reinemund J, Gevers E, Sarri M, Downes K, Offiah A, Albanese A, Halsall D, Schwabe JW, Bain M, Lindley K, Muntoni F, Vargha-Khadem F, Dattani M, Farooqi IS, Gurnell M, Chatterjee K 2012 A mutation in the thyroid hormone receptor alpha gene. N Engl J Med 366:243-249.

9. van Mullem A, van Heerebeek R, Chrysis D, Visser E, Medici M, Andrikoula M, Tsatsoulis A, Peeters R, Visser TJ 2012 Clinical phenotype and mutant TRalpha1. N Engl J Med 366: 1451-1453.

10. van Gucht ALM, Moran C, Meima ME, Visser WE, Chatterjee K, Visser TJ, Peeters RP 2017 Resistance to thyroid hormone due to heterozygous mutations in thyroid hormone receptor alpha. Curr Top Dev Biol 125:337-355.

11. Moran C, Chatterjee K 2016 Resistance to thyroid hormone alpha-emerging definition of a disorder of thyroid hormone action. J Clin Endocrinol Metab 101:2636-2639.

12. Moran C, Schoenmakers N, Agostini M, Schoenmakers E, Offiah A, Kydd A, Kahaly G, Mohr-Kahaly S, Rajanayagam O, Lyons G, Wareham N, Halsall D, Dattani M, Hughes S, Gurnell M, Park SM, Chatterjee K 2013 An adult female with resistance to thyroid hormone mediated by defective thyroid hormone receptor alpha. J Clin Endocrinol Metab 98:4254-4261.

13. Tylki-Szymanska A, Acuna-Hidalgo R, KrajewskaWalasek M, Lecka-Ambroziak A, Steehouwer M, Gilissen C, Brunner HG, Jurecka A, Rozdzynska-Swiatkowska A, Hoischen A, Chrzanowska KH 2015 Thyroid hormone resistance syndrome due to mutations in the thyroid hormone receptor alpha gene (THRA). J Med Genet 52:312-316.

14. Demir K, van Gucht AL, Buyukinan M, Catli G, Ayhan Y, Bas VN, Dundar B, Ozkan B, Meima ME, Visser WE, Peeters RP, Visser TJ 2016 Diverse genotypes and phenotypes of three novel thyroid hormone receptor-alpha mutations. J Clin Endocrinol Metab 101:2945-2954.

15. Moran C, Agostini M, Visser WE, Schoenmakers E, Schoenmakers N, Offiah AC, Poole K, Rajanayagam O, Lyons G, Halsall D, Gurnell M, Chrysis D, Efthymiadou A, 
Buchanan C, Aylwin S, Chatterjee KK 2014 Resistance to thyroid hormone caused by a mutation in thyroid hormone receptor (TR)alpha1 and TRalpha2: clinical, biochemical, and genetic analyses of three related patients. Lancet Diabetes Endocrinol 2:619-626.

16. Espiard S, Savagner F, Flamant F, Vlaeminck-Guillem V, Guyot R, Munier M, d'Herbomez M, Bourguet W, Pinto G, Rose C, Rodien P, Wemeau JL 2015 A novel mutation in THRA gene associated with an atypical phenotype of resistance to thyroid hormone. J Clin Endocrinol Metab 100:2841-2848.

17. Kalikiri MK, Mamidala MP, Rao AN, Rajesh V 2017 Analysis and functional characterization of sequence variations in ligand binding domain of thyroid hormone receptors in autism spectrum disorder (ASD) patients. Autism Res 10:1919-1928.

18. Moran C, Agostini M, McGowan A, Schoenmakers E, Fairall L, Lyons G, Rajanayagam O, Watson L, Offiah A, Barton J, Price S, Schwabe J, Chatterjee K 2017 Contrasting phenotypes in resistance to thyroid hormone alpha correlate with divergent properties of thyroid hormone receptor alpha1 mutant proteins. Thyroid 27:973-982.

19. van Gucht AL, Meima ME, Zwaveling-Soonawala N, Visser WE, Fliers E, Wennink JM, Henny C, Visser TJ, Peeters RP, van Trotsenburg AS 2016 Resistance to thyroid hormone alpha in an 18-month-old girl: clinical, therapeutic, and molecular characteristics. Thyroid 26:338-346.

20. Wejaphikul K, Groeneweg S, Hilhorst-Hofstee Y, Chatterjee VK, Peeters RP, Meima ME, Visser WE 2019 Insight into molecular determinants of $\mathrm{T} 3 \mathrm{vs}$. T4 recognition from mutations in thyroid hormone receptor alpha and beta. $\mathrm{J}$ Clin Endocrinol Metab 104:3491-3500.

21. Clifton-Bligh RJ, de Zegher F, Wagner RL, Collingwood TN, Francois I, Van Helvoirt M, Fletterick RJ, Chatterjee VK 1998 A novel TR beta mutation (R383H) in resistance to thyroid hormone syndrome predominantly impairs corepressor release and negative transcriptional regulation. Mol Endocrinol 12:609-621.

22. Safer JD, Cohen RN, Hollenberg AN, Wondisford FE 1998 Defective release of corepressor by hinge mutants of the thyroid hormone receptor found in patients with resistance to thyroid hormone. J Biol Chem 273:30175-30182.

23. Huber BR, Desclozeaux M, West BL, Cunha-Lima ST, Nguyen HT, Baxter JD, Ingraham HA, Fletterick RJ 2003 Thyroid hormone receptor-beta mutations conferring hormone resistance and reduced corepressor release exhibit decreased stability in the N-terminal ligand-binding domain. Mol Endocrinol 17:107-116.

24. Collingwood TN, Wagner R, Matthews $\mathrm{CH}$, Clifton-Bligh RJ, Gurnell M, Rajanayagam O, Agostini M, Fletterick RJ, Beck-Peccoz P, Reinhardt W, Binder G, Ranke MB, Hermus A, Hesch RD, Lazarus J, Newrick P, Parfitt V, Raggatt P, de Zegher F, Chatterjee VK 1998 A role for helix 3 of the TRbeta ligand-binding domain in coactivator recruitment identified by characterization of a third cluster of mutations in resistance to thyroid hormone. EMBO J 17:4760-4770.

25. Collingwood TN, Adams M, Tone Y, Chatterjee VK 1994 Spectrum of transcriptional, dimerization, and dominant negative properties of twenty different mutant thyroid hormone beta-receptors in thyroid hormone resistance syndrome. Mol Endocrinol 8:1262-1277.

26. Wejaphikul K, Groeneweg S, Dejkhamron P, Unachak K, Visser WE, Chatterjee VK, Visser TJ, Meima ME, Peeters RP 2018 Role of leucine 341 in thyroid hormone receptor beta revealed by a novel mutation causing thyroid hormone resistance. Thyroid Nov [Epub ahead of print]; DOI 10.1089/thy.2018.0146.

27. Mol JA, Visser TJ 1985 Synthesis and some properties of sulfate esters and sulfamates of iodothyronines. Endocrinology 117:1-7.

28. Nascimento AS, Dias SM, Nunes FM, Aparicio R, Ambrosio AL, Bleicher L, Figueira AC, Santos MA, de Oliveira Neto M, Fischer H, Togashi M, Craievich AF, Garratt RC, Baxter JD, Webb P, Polikarpov I 2006 Structural rearrangements in the thyroid hormone receptor hinge domain and their putative role in the receptor function. J Mol Biol 360:586-598.

29. Krieger E, Vriend G 2014 YASARA view-molecular graphics for all devices-from smartphones to workstations. Bioinformatics 30:2981-2982.

30. Krieger E, Koraimann G, Vriend G 2002 Increasing the precision of comparative models with YASARA NOVA-a self-parameterizing force field. Proteins 47:393-402.

31. Liu YY, Schultz JJ, Brent GA 2003 A thyroid hormone receptor alpha gene mutation $(\mathrm{P} 398 \mathrm{H})$ is associated with visceral adiposity and impaired catecholamine-stimulated lipolysis in mice. J Biol Chem 278:38913-38920.

32. Kitajima K, Nagaya T, Jameson JL 1995 Dominant negative and DNA-binding properties of mutant thyroid hormone receptors that are defective in homodimerization but not heterodimerization. Thyroid 5:343-353.

33. Yen PM, Wilcox EC, Hayashi Y, Refetoff S, Chin WW 1995 Studies on the repression of basal transcription (silencing) by artificial and natural human thyroid hormone receptor-beta mutants. Endocrinology 136:2845-2851.

34. Paquette MA, Atlas E, Wade MG, Yauk CL 2014 Thyroid hormone response element half-site organization and its effect on thyroid hormone mediated transcription. PLoS One 9:e101155.

35. Chen Y, Young MA 2010 Structure of a thyroid hormone receptor DNA-binding domain homodimer bound to an inverted palindrome DNA response element. Mol Endocrinol 24:1650-1664.

36. Collingwood TN, Rajanayagam O, Adams M, Wagner R, Cavailles V, Kalkhoven E, Matthews C, Nystrom E, Stenlof K, Lindstedt G, Tisell L, Fletterick RJ, Parker MG, Chatterjee VK 1997 A natural transactivation mutation in the thyroid hormone beta receptor: impaired interaction with putative transcriptional mediators. Proc Natl Acad Sci U S A 94:248-253.

37. Yoh SM, Chatterjee VK, Privalsky ML 1997 Thyroid hormone resistance syndrome manifests as an aberrant interaction between mutant $\mathrm{T} 3$ receptors and transcriptional corepressors. Mol Endocrinol 11:470-480.

38. Harrus D, Demene H, Vasquez E, Boulahtouf A, Germain P, Figueira AC, Privalsky ML, Bourguet W, le Maire A 2018 Pathological interactions between mutant thyroid hormone receptors and corepressors and their modulation by a thyroid hormone analogue with therapeutic potential. Thyroid 28:1708-1722.

Address correspondence to: Marcel E. Meima, PhD Department of Internal Medicine Erasmus $M C$ Academic Center for Thyroid Diseases Wytemaweg 80

Rotterdam 3015 CN The Netherlands

E-mail: m.meima@erasmusmc.nl 